\title{
Repeated implantation failure in oocyte donation. What to do to improve the endometrial receptivity?
}

\author{
Alberto E. Tersoglio ${ }^{1}$, Dante R. Salatino ${ }^{1}$, Gisela Reinchisi ${ }^{1}$, Adriana Gonzalez ${ }^{2}$, Sebastian Tersoglio ${ }^{1}$, Cristian \\ Marlia $^{1}$ \\ ${ }^{1}$ International Center for Assisted Reproduction, Mendoza, Argentina \\ 2Medical Director Immunology Laboratory, Central Hospital, Mendoza, Argentina
}

\begin{abstract}
Objective: To determine the role of polyvalent endometrial treatment in patients undergoing IVF-ET who had recurrent implantation failure (RIF) in a program of oocyte donation (OD). The results were expressed in terms of live birth rate (LBR). Secondly analyze changes of endometrial leukocyte population evaluated by flow cytometer (FC) and histopathology.

Methods: Prospective study of a model-based control with analog abductive methodology. Over initial population of 75 patients with RIF in ovodonation, thirty cycles / patient of IVF/ET were selected in this study. A control group of 12 patients was established to variables FC. All patients were transferred to day 5-6 with a maximum of 2 expanded blastocysts with at least one of optimum quality. A versatile treatment was applied in all cases with both assessments in pre and postreatment.

Results: Chronic endometritis was diagnosed in $14 / 30$ $(46.7 \%)$ with endometrial identifying germs in $12 / 30$ $(40 \%)$ and $6 / 30(20 \%)$ was associated with endometrial thinning. A significant increase in endometrial thickness associated with a decrease in abnormal histopathology and $\mathrm{Li} / \mathrm{PC}$ was observed at postreatment in relation with a pretreatment $(P=0.047$ and $P=0.002)$ respectively. An increase of uterine killer cells ( $\mathrm{Nku}$ ) was observed in postreatment in absence of pregnancy. CD4/CD3 was established with prognostic value when their values are close to those of the control group.

Conclusion: Our findings demonstrate the reversibility of endometrial histological changes, both sonographics as immunological in RIF group under a polyvalent therapeutic; which is capable of modifying the immunology and endometrial histopathology and to obtain live birth.
\end{abstract}

Keywords: In vitro fertilization, Chronic Endometritis, Recurrent Implantation Failure, Endometrial Biopsy, Endometrial Flow Cytometry.

\section{INTRODUCTION}

Recurrent Implantation Failure (RIF) should be considered a nosological entity resulting from repeated cycles of IVF (In Vitro Fertilization) / ICSI (Intracytoplasmic Sperm Injection) that failed with optimal embryo quality in transfer. Recent reports support the need for such consideration and defined as the absence of implantation after 2 consecutive cycles in IVF / ICSI or cryotransfer (embryo frozen replacement), where the cumulative number of embryos transferred was not less than 4 embryos at cleavage or two blastocysts, all of good quality; concept extended to egg donation (Polanski et al., 2014; Coughlan et al., 2014).

Dismissing embryo quality as a key factor in the implantatory success, the endometrium becomes the main object of study (Strowitzki et al., 2006). Difficulties in human research, to access of the peri-implantation endometrium without compromising the nesting challenges us to find new models of clinical research to address the failure of implantation. The egg donation has been proposed as an attractive model for this purpose, even when other factors have not allowed to isolate the endometrium as a primary factor (Zenke \& Chetkowski, 2004).

The implantation of the embryo in the maternal decidua is a complex process involving embryonic events, uterine epithelial maturation, cyclic hormonal changes in the mother and the participation of local and systemic immune response. The implantatory niche is the result of the interaction of at least four cell groups: stromal, epithelial, endothelial and immune cells (Navot et al., 1991). The immune process that is developed in implantation is active and controlled; ultimately modulated (Mor \& Cardenas, 2010).

Given the importance that in recent years had the study of immune reactions at the maternal-embryonic interface as a possible cause of RIF, we will give some detail of uterine leukocyte population involved in modulating the state of immune tolerance that allows maintenance of pregnancy. Of the endometrial lymphocyte population that comes to represent, on average, $10 \%$ of its population cell (Bryceson et al., 2006) we highlight some of its cellular elements. The B-lymphocytes of little presence on the endometrium, macrophages, which comprise $20 \%$ of all leukocytes in the decidua, being the main subpopulation the producer of human leucocyte antigen (HLA) who exhibit a high level of plasticity and are considered as antigen presenting (Nagamatsu \& Schust, 2010). T lymphocytes (TL), representing 30 to $45 \%$ of the total lymphocytes (Lachapelle et al., 1996; Quenby et al., 2009). The T regulatory cells CD4+ CD25+ (Treg) derived from LT are observed in the early stages of pregnancy, and they are considering themselves accountable of self-tolerance to protect the paternal cells (Mjösberg et al., 2007; Mjösberg et al., 2010). The NK cells, the main constituent of lymphocytic population in the endometrial mucosa have been extensively studied in women with RIF or with repeated fetal loss; concluding that the deregulation of NK cells could be relevant in these cases. (Beer et al., 1996; Coulam \& Roussev, 2003). The plasmatic NK cells (NKP) are part of the innate immunity, with an antiviral and antineoplastic function; while the uterine NK cells (NKu) are characterized by a low cytotoxic activity and be a powerful source of cytokines (Bulmer \& Lash, 2005). The endometrial NK are granular lymphocytes identified by the loss of CD3+ and expressing CD56, manifested with different densities, and with a considerable increase in the secretory and implantation phases (Manaster et al., 2008). The absolute number of $\mathrm{NKu}$ is increased in the late secretory phase and in the implantation, but as the total lymphocyte population also increases, the NKu ratio remains roughly constant at a value of 30-45\% (Ho et al., 1996; Lachapelle et al., 1996).

The primary objective of this paper is to analyze in a population of RIF in egg donation, the results of a polyvalent endometrial treatment, where the factors of heterogeneity were excluded in order to isolate the endometrium as the main actor, to assess its effectiveness in terms of live birth rate (LBR) per cycle transferred. As a secondary 
objective we propose to analyze the changes of endometrial leukocyte population evaluated by endometrial flow cytometry and endometrial histopathology, implemented in response to the therapy.

\section{MATERIAL AND METHODS}

\section{Methodology}

If in this paper we apply only the hypothetical-deductive method, we could say it is a case-control study, retrospective and prospective, quasi-experimental. However, as will be besides addressed from an analogical-adductive methodology, we say that is also a prospective control based on a model. The abductive method is suggested when an investigation starts from the observation of the results, as in this case, and the interest of the study is focused on a particular element of those considered when designing the system to be analyzed. Here, this element is the endometrium. The abductive method, created by Peirce, extended by Samaja and completed by Salatino, permits, building on the results and taking as a rule of a known phenomenon, discover the hypothesis (as he called Peirce) (Peirce, 1992; Samaja, 1999; Salatino, 2009). That is, reach a valid conclusion, projecting the praxis to the theory through successive approximations.

As shown in the previous figure (upper triangle), the complementary logical scientific method adopted in this study can be defined as metaphorical by analogy; where analogy allows to discover the hidden model that gives us the general rule or law. This is applied to a known domain (the endometrium or source) to explore an unknown domain (the implant or destination). While the metaphor takes the opposite way, applied the law, according to the model, you can see the results on the surface, by the im- portance of change achieved (live birth rate positive in RIF treated). The abduction allows separate the superficial and deep levels (individualization), whereas adduction, approximates these levels until make them simultaneous, leading to a universalization. In the left-down triangle, is presented a comprehensive overview of possible research methods, and what we are doing when we use them. As you can see, in the abduction, we employ an individualization, however, in adduction is where are made fewer mistakes of appreciation (judgment) by using a universalization rather than a generalization by interpolation, or a particularization by extrapolation. The triangle at the bottom (Figure 1) right tells us about the application of adduction to our research, and what is its logical performance. The cycle that turns left (profound) tells us about the implementation of a treatment to try improve some endometrial conditions, assuming a quality of optimal blastocyst, which, once achieved, leads to a superficial cycle (the implant, of rotation right) that lasts over time, until the end of pregnancy.

\section{Definition of RIF}

We consider RIF as the absence of implantation after two or more cycles of IVF / ICSI or cryotransfer, where the cumulative number of embryos transferred was no less than two blastocysts with quality 311-511 of Gardner-Schoolcraft, under the criteria of Istanbul (Alpha Scientists in Reproductive and ESHRE special interest group of Embryology, 2012).

\section{Patient selection}

Over an initial population of $(n=75)$ cases RIF in oocyte donation in the period 2010-2013, 30 cycle/patient

Figure 1. ANALOGICAL-ADDUCTIVE METHOD (Based in Salatino, 2009)

References: $\mathrm{Sp}=$ superficial $-\mathrm{P}=$ profound $-\mathrm{S}=$ subject $-\mathrm{O}=$ object $-\mathrm{V}=$ superficial change $-\nabla=$ hidden change

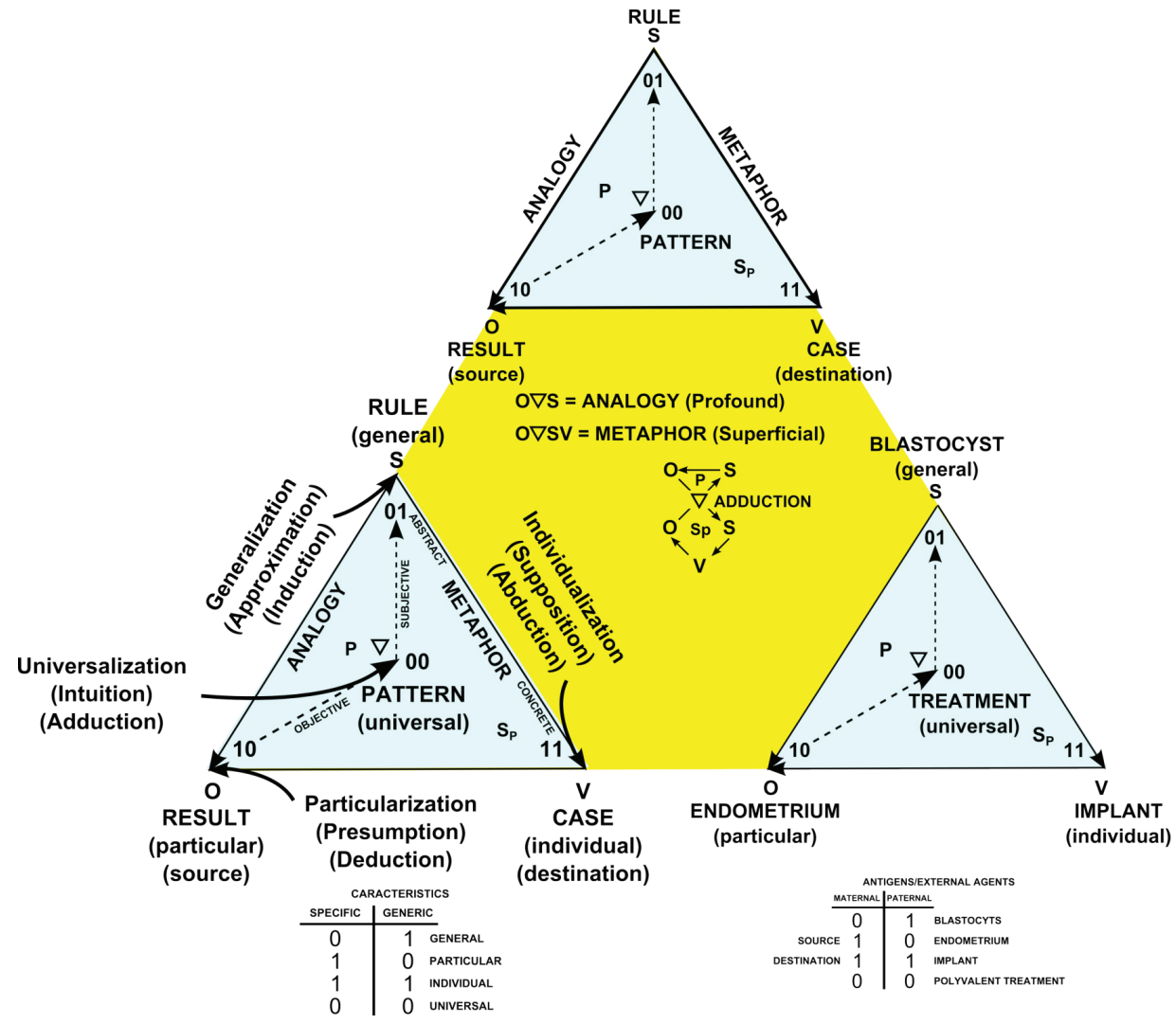


they were assigned to the analysis and defined as such. Exclusion criteria were: uterine malformation; autoimmune thyroid disease; presence of Ac. Antiphospholipid ( $n$ $=2$ ); abnormal uterine cavity ascertained by hysterosalpingography, hysteroscopy or hysterosonography; presence of myomas $(n=1)$; polyps $(n=4)$, hydrosalpinx $(n=1)$; embryo quality criteria suboptimal for Gardner-Schoolcraft modified, and those who did not complete histopathological evaluation and endometrial cytometric, pre and post treatment $(n=37)$.

It was established a control group for the cytometric variables ( $n=12)$, corresponding to oocyte donors with a normal reproductive history (absence of abortions, with normal live births, no history of vaginosis, negative endometrial bacteriology, normal endometrial pathological anatomy); where the same exclusion criteria of the study group were considered. The endometrial cytometric parameters found, were considered as controls.

Endometrium. Biopsy, immunological, histological, bacteriological and ultrasound parameters

Biopsies were performed at +5 day of the $\mathrm{LH}$ surge in the control group, and the 5th day of exogenous progesterone in receptor both in the diagnostic phase as after treatment; the latter prior to IVF cycle. The takes biopsy was obtained with biopsy cannula Pipelle (CCD) under negative pressure trying to get as much of endometrial tissue by means of rotational movements and displacement in the longitudinal axis according to described technique. Biopses prior to the IVF cycle had a second objective: besides to evaluate the treatment, to carry out endometrial injury. It was considered an optimal decision when the light of the cannula was filled with the typical endometrial tissue, with low haematic contamination. The biopsies were divided in 3 samples. The first to flow cytometry, the second to Histopathology, and the last to bacteriological evaluation.

The cytometric evaluation was conducted by a trademark equipment CyFlow $^{\circledR}$ Counter.
The following variables were considered: Li / PC (relation total lymphocyte / total cell population), ratio of $T$ lymphocytes (LT), B lymphocytes (LB) and NK (NK) cells over $\mathrm{Li} ; \mathrm{CD} 3+\mathrm{CD} 4+$ and $\mathrm{CD} 3+\mathrm{CD} 8+$ in relation to Radio CD4 / CD8, and NK CD56 /CD16 subpopulations on NK.

The histopathological criteria for dating were those of Noyes (Noyes et al., 1950); the endometritis was diagnosed in the presence of plasma cells and polymorphonuclear stromal localization (Greenwood \& Moran, 1981; Eschenbach, 2008) with at least $\geq 1$ plasma cells per High Power Field (HPF) (Johnston-MacAnanny et al., 2010).

The bacteriological examination consisted in fresh exam with Gram and Giemsa and culture on Thayer Martin medium, sheep blood agar, and chocolate agar, Agar medium Saboreaud and EMB / CLDE. Investigation of Chlamydia trachomatis by immunofluorescence, Mycoplasma hominis and ureaplama urealyticum by Mycofast-urea/ arginine.

Endometrial thickness was defined as the maximum distance between the echogenic interfaces of the myometrium and endometrium measured in the plane of the central longitudinal axis of the uterus and evaluated to the day of human chorionic gonadotropin (HCG) of oocyte donor, considering cutoff value for endometrial thinned $\leq 7 \mathrm{~mm}$.

\section{Endometrial therapy}

All the patients received corticosteroid therapy in doses meprednisone orally 4 to 8 daily mg; Glycine 100 $\mathrm{mg} /$ day associated with Vit. E $300 \mathrm{mg}$, Vit. B6 $100 \mathrm{mg}$ and Vit. A $10.000 \mathrm{UI} /$ day orally; specific antibiotic therapy in the case where there was germ identification. Where it was not possible to isolate specific germ, was administered Doxycycline $200 \mathrm{mg} /$ day during fourteen days, continuing with an association of metronidazole $1 \mathrm{~g} /$ day and ciprofloxacin $1 \mathrm{~g} /$ day for 14 days. In cases where no remission of the inflammatory process is achieved, the above scheme is repeated, associating Linezolid $600 \mathrm{mg} /$ day orally for 10 days. In cases of endometrial thinning, were instilled Filgrastim $300 \mu \mathrm{g}$ of $1 \mathrm{ml}$ intrauterine, on

Table 1. Patient and clinical characteristics in group RIF ( recurrent implantation failure)

\begin{tabular}{|l|l|}
\hline Characteristics & RIF group \\
\hline Number of cycles & 30 \\
\hline Number of previous cycles IVF failed & $3.2 \pm 1.1(2-6)$ \\
\hline Patient age (year) & $36 \pm 4.08(30-46)$ \\
\hline Length of sterility (year) & $9 \pm 7(4-20)$ \\
\hline Endometrial thickness (mm) & $8.77 \pm 2.12(6-13)$ \\
\hline Thinned endometrium < 7mm (mm) & $6 / 30(20 \%)$ \\
\hline Positive endometrial bacteriology & $12 / 30(40 \%)$ \\
\hline Mycoplasma/Ureaplasma & $5 / 12(41.6 \%)$ \\
\hline Clamydias & $3 / 12(25 \%)$ \\
\hline Bacteria G(-)* and G(+) + & $4 / 12(33.3 \%)$ \\
\hline Endometrial biopsy & $16 / 30(53.3 \%)$ \\
\hline Absence of chronic endometritis (CE) & $14 / 30(46.7 \%)$ \\
\hline Chronic endometritis (CE) $\neq$ & $7 / 30(23.3 \%)$ \\
\hline Micropolyposis & $6 / 14(42.8 \%)$ \\
\hline in CE & $1 / 16(6.2 \%)$ \\
\hline in absence CE & \\
\hline$\%$ & \\
\hline
\end{tabular}

*(2 Enterococcus Faecalis. 1 Eikinella cannis $)+(1$ beta hemolytic streptococcus $)$

$\neq 13$ chronic endometritis. 1 diffuse Endometritis 


\begin{tabular}{|c|c|c|c|c|}
\hline Variables & Control & $\begin{array}{c}\text { RIF } \\
\text { Pretreatment }\end{array}$ & $\begin{array}{c}\text { RIF } \\
\text { Posttreatment }\end{array}$ & $\boldsymbol{P}$ \\
\hline Endometrial thickness (mm) & $9.5 \pm 1.2(7.5-11)^{*}$ & $8.77 \pm 2.12(6-13) \dagger$ & $9.77 \pm 3.35(5.7-13) \neq$ & $0.047+\neq$ \\
\hline Abnormal pathology & - & $16 / 30(53.3) \dagger$ & $5 / 30(16.6) \neq$ & $0.0012 t \neq$ \\
\hline \multicolumn{5}{|l|}{ Flow Cytometry (FC) } \\
\hline $\mathrm{Li} / \mathrm{PC}$ & $10.1 \pm 4.4(4-16) *$ & $17.3 \pm 8.2(4-35) \dagger$ & $8.9 \pm 8.3(2-45) \neq$ & $0.01 *+0.002+\neq$ \\
\hline LT/Li & $46.8 \pm 24.8(2-85)$ & $46.6 \pm 19.3(11-77)$ & $49.3 \pm 18.09(14-81)$ & NS \\
\hline $\mathrm{LB} / \mathrm{Li}$ & $2.9 \pm 2.4(0-7)$ & $2.2 \pm 2.2(0-8)$ & $2.25 \pm 1.7(0-7)$ & NS \\
\hline $\mathrm{NK} / \mathrm{Li}$ & $40.2 \pm 21.6(13-68)$ & $48.02 \pm 20.9(19-88)$ & $47.08 \pm 18.2(15-85)$ & NS \\
\hline CD3+CD4/LTCD3+ & $44 \pm 8.15(29-56)$ & $48.1 \pm 11.8(20-69)$ & $43.6 \pm 10.2(20-65)$ & NS \\
\hline CD3+CD8/LTCD3+ & $53.2 \pm 8.52(42-66)$ & $51.6 \pm 10.7(31-80)$ & $54.7 \pm 8.9(35-80)$ & NS \\
\hline CD4/CD8 & $0.92 \pm 0.26(0-1)$ & $1.02 \pm 0.45(0.25-2.22)$ & $0.85 \pm 0.3(0.25-1.85)$ & NS \\
\hline NKCD56dimCD16bright/NK & $14.5 \pm 7.32(4-30)$ & $14.42 \pm 11.44(3-48)$ & $17.94 \pm 12.03(4-44)$ & NS \\
\hline NKCD56brightCD16dim/NK & $84.07 \pm 8.02(68-96)$ & $83.63 \pm 13.77(41-97)$ & $80.14 \pm 12.37(55-96)$ & NS \\
\hline
\end{tabular}

Values are mean \pm SD (range).

the day of progestin initiation of supplementation.

\section{Receptor protocol}

In the presence of ovarian activity hypothalamic suppression was performed with the use of depot GnRHa, Triptorelin $3.76 \mathrm{mgr}$ in single dose, or Leuprolide acetate in doses of 200 to $300 \mu \mathrm{g} /$ day, in long regime; beginning the estrogen replacement, in the presence of a plasmatic estradiol $<30 \mathrm{pg} / \mathrm{ml}$. Both the Estradiol valerate, as the 17 B-estradiol was administered in increasing doses, orally, according to the endometrial response and established protocol. In cases of inadequate endometrial response was associated with transdermal replacement variable dose of 50-150 micrograms (in patches) every 2.5 days.

\section{Assisted Hatching}

In cases of absence of spontaneous hatching, was performed the technique of Tyrode two hours prior to the transfer according to protocol of Hogan (Hogan et al., 1986).

\section{Criteria embryo transfer and intervention}

Embryo culture to day 5 embryo transfer with at least one blastocyst with high quality (score 311-511 according to the criteria of Istanbul) were transferred up to 2 blastocysts of good quality embryos (511 or 411), when one of them was of good quality, the second was of suboptimal quality $(412,421,512$ or 521$)$; in case of single embryo transfer (SET) was considered only optimal quality.

\section{Statistical Analysis}

Cytometric data and descriptive results were analyzed with SPSS version 20. Results are presented as mean \pm SD (range). Shapiro-Wilk test is applied to evaluate normality. In comparative tests was applied t-student or U-Mann-Whitney test for independent samples. In the longitudinal temporal analysis, statistical test used was t-student for dependent samples or Wilcoxon test, depending on normality. $P<0.05$ was considered statistically significant, in the cases of significance the $P$ value was expressed numerically to two decimal places and not significance as (NS). Odds Ratio (OR) was calculated with a confidence interval (CI) of $95 \%$.

The results were expressed in terms of LBR (our standard measure) per procedure/patient. Live birth was de- fined as a pregnancy that ended with delivery of live infant(s). Clinical pregnancy was defined by visualization of a gestational sac with a positive fetal heartbeat after 3-5 weeks of the transfer; as pregnancy ongoing when the evolution was more than 14 weeks with embryonic vitality. A Clinical abortion was defined as a pregnancy loss before gestational week 12, after sonography visualization of an intrauterine gestational sac at 5 to 6 weeks of gestation.

\section{RESULTS}

A total of $30 \mathrm{cycles} /$ patient were analyzed with a mean age of $36 \pm 4.08$ (30-46) years, with a history of infertility of $9 \pm 7$ (4-20) years and a mean of $3.2 \pm 1.1$ (2-6) previous failed cycles. In pretreatment endometrial thickness (ET) at day 0 of $8.77 \pm 2.12$ was observed. In $6 / 30(20 \%)$ was $\leq 7 \mathrm{~mm}$. The endometrial bacteriology was positive in $12 / 30(40 \%)$, mycoplasma hominis was identified in $5 / 12(41.6 \%)$, chlamydial trachomatis in 3/12 (25\%) and G- bacteria in $4 / 12(33 \%)$. The histopathology was normal in $16 / 30(53,3 \%)$ and chronic endometritis in $14 / 30$ $(46,7 \%)$. Mycropoliposis was associated in high percentage with EC in 6/14 (42,8\%) (Table 1 ).

A multiple comparison between the control groups and RIF pretreatment and posttreatment based on the variables (endometrial thickness, histopathology and endometrial flow cytometry eFC) resulted in a decreased endometrial thickness RIF pretreatment group compared to the posttreatment group $(P=0.047)$. The concentration of $\mathrm{Li} / \mathrm{PC}$ in the pretreatment was a significantly higher compared to the control group $(P=0.01)$. Posttreatment shows a significant decrease of abnormal histopathology with positive criteria for EC and concentration of Li/PC compared to pretreatment ( $P=0.0012$ and 0.002 ) (Table 2).

LBR+ not show difference in relation to endometrial thickness between before and after treatment, and a significant decrease in abnormal histopathology at post-treatment $(P=0.0031)$. However, LBR- did not show modification in abnormal histopathology. In cases with live births a statistically significant decrease of Li/PC post-treatment $(P=0.0045)$ was observed, with a trend NS to decrease of NK/Li $(P=0.078)$. In the absence of live births was observed a similar behavior to the first Li/PC $(P=0.03)$, with a significant increase in $\mathrm{NK} / \mathrm{Li}(P=0.045)$ in the post-treatment (Table 3).

At post-treatment, all the cytometric variables are pa- 
Table 3. RIF Pretreatment X RIF Pos Treatment : Cytometric Parametres

\begin{tabular}{|c|c|c|c|}
\hline Cytometric Parametres & RIF Pretreatment & RIF Postreatment & $\boldsymbol{P}$ \\
\hline \multicolumn{4}{|l|}{ LBR+ } \\
\hline Endometrial thickness (mm) & $8.8 \pm 2(6-13)$ & $9.64 \pm 2.18(6-13)$ & NS \\
\hline Anormal pathology & $8 / 16(50)$ & $1 / 16(6.2)$ & 0.0031 \\
\hline \multicolumn{4}{|l|}{ CFE } \\
\hline $\mathrm{Li} / \mathrm{PC}$ & $18.18 \pm 8.3(6-32)$ & $6.91 \pm 4.67(2-16)$ & 0.0045 \\
\hline LT/Li & $48.64 \pm 20.4(16-71)$ & $52.55 \pm 14(38-69)$ & NS \\
\hline LB/Li & $1.64 \pm 1.5(0-5)$ & $1.45 \pm 2.16(0-5)$ & NS \\
\hline $\mathrm{NK} / \mathrm{Li}$ & $46.73 \pm 21.87(22-82)$ & $36.55 \pm 13.9(15-57)$ & 0.078 \\
\hline CD3+CD4/LTCD3+ & $49.40 \pm 9.83(33-64)$ & $47 \pm 7.9(38-65)$ & NS \\
\hline CD3+CD8/LTCD3+ & $50.64 \pm 9.3(36-67)$ & $52.18 \pm 7.75(35-62)$ & NS \\
\hline CD4/CD8 & $1.04 \pm 0.39(0.49-1.77)$ & $0.94 \pm 0.35(0.6-1.8)$ & NS \\
\hline NK CD56dimCD16bright & $17.56 \pm 12.7(5-39)$ & $19.5 \pm 11.9(7-44)$ & NS \\
\hline NKCD56brightCD16dim & $80.22 \pm 14.66(53-95)$ & $78.5 \pm 12.69(55-93)$ & NS \\
\hline \multicolumn{4}{|l|}{ LBR- } \\
\hline Endometrial thickness (mm) & $8.4 \pm 2.3(6-12)$ & $9.3 \pm 1.7(8-13)$ & NS \\
\hline Anormal pathology & $8 / 14(57.1)$ & $4 / 14(28.57)$ & NS \\
\hline \multicolumn{4}{|l|}{ CFE } \\
\hline $\mathrm{Li} / \mathrm{PC}$ & $15.57 \pm 6.52(4-26)$ & $6.85 \pm 3.89(3-15)$ & 0.03 \\
\hline $\mathrm{LT} / \mathrm{Li}$ & $47.85 \pm 11.29(36-65)$ & $41.57 \pm 14.79(22-69)$ & NS \\
\hline LB/Li & $5.42 \pm 4.79(0-11)$ & $2.57 \pm 1.39(1-4)$ & NS \\
\hline $\mathrm{NK} / \mathrm{Li}$ & $40.42 \pm 15.70(20-62)$ & $55 \pm 13.8(30-75)$ & 0.045 \\
\hline CD3+CD4/LTCD3+ & $42.71 \pm 15.27(20-65)$ & $44 \pm 8.48(35-55)$ & NS \\
\hline CD3+CD8/LTCD3+ & $55.28 \pm 14.12(35-80)$ & $54 \pm 6.45(45-63)$ & NS \\
\hline CD4/CD8 & $0.88 \pm 0.53(0.25-1.85)$ & $0.88 \pm 0.26(0.59-1.22)$ & NS \\
\hline NK CD56dimCD16bright & $12.42 \pm 16.0(3-48)$ & $11.71 \pm 4.34(7-20)$ & NS \\
\hline NKCD56brightCD16dim & $85.28 \pm 19.98(41-97)$ & $86.42 \pm 7.04(72-93)$ & NS \\
\hline
\end{tabular}

Table 4. OR for CD4 post treatment regarding with result.

\begin{tabular}{|c|c|c|c|}
\hline & LBR+ & LBR- & OR (CI) \\
\hline CD4 NORMAL & $82.40 \%$ & $33.00 \%$ & \\
\hline CD4 ABNORMAL & $17.60 \%$ & $67.00 \%$ & \\
\hline
\end{tabular}

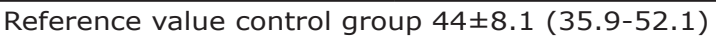

rameterized taking as reference the values of the control group relative to LBR group. Resulting in only CD4CD3+ with a significant interval of confidence and an OR of 9.3 CI 1.6 to 52.6 for LBR+. Concluding that when the variable CD4 approaches to the control values, the ratio of chance to obtain a born alive is 9.3 times higher than those who did not succeed (Table 4).

A similar analysis for endometrial histopathology, results in an OR: 6.75 (0.64 to 61.1) (NS) for LBR+ when the endometrium is normalized after treatment compared with persistent CE. In all cases with positive endometria bacteriology I ( $n=12$ ) was obtained negativation in the posttreatment.

Clinical results after interventions in the group RIF are evaluated according to: initial absence of CE, on which they were then normalized of the treatment, and those on which EC persisted. The persistent CE showed a significant decrease in the implantation rate relative to absence of CE and the posttreatment normalization, $(P=0.05$ and $P$ $=0.042$, respectively). While the CE normalized at posttreatment achieved the highest rate of implantation, the abortion rate was strikingly higher than in subgroups of 


\begin{tabular}{|c|c|c|c|c|c|}
\hline Characteristics & $\begin{array}{c}\text { RIF group } \\
\text { posttreatment }\end{array}$ & $\begin{array}{c}\text { Absence of } \\
\text { CE* }\end{array}$ & $\begin{array}{l}\text { Normalized CE } \\
\text { posttreatment }+\end{array}$ & $\begin{array}{c}\text { Persistent } \\
\text { CE } \neq\end{array}$ & $\boldsymbol{P}$ \\
\hline $\mathrm{N}$ & 30 & 16 & 9 & 5 & - \\
\hline Implantation rate $(\%)$ & 59.7 & 59.32 & 75.72 & 36.6 & $0.05 * \neq-0.042 \dagger \neq$ \\
\hline Clinical pregnancy rate(\%) & $23 / 30(76.6)$ & $13 / 16(81.25)$ & $9 / 0(100)$ & $3 / 5(60)$ & NS \\
\hline Abortion rate(\%) & $7 / 30(23.3)$ & $3 / 16(18.75)$ & $3 / 9(33.3)$ & $1 / 5(20)$ & NS \\
\hline Ongoing pregnancy rate(\%) & $16 / 30(53.3)$ & $10 / 16(62,5$ & $6 / 9(66.6)$ & $2 / 5(40)$ & NS \\
\hline Live birth rate per cycle(\%) & $16 / 30(53.3)$ & $10 / 16(62.5)$ & $6 / 9(66.6)$ & $2 / 5(40)$ & NS \\
\hline
\end{tabular}

ANOVA one way*+‡

absence and persistence EC, even if the difference is NS. In the presence of persistent EC were obtained the lowest rates of pregnancy and live birth (Table 5).

\section{DISCUSSION}

The analysis of the endometrium remains a challenge. Inaccessibility of it at the time of embryo transfer in IVF and scarce resources to assess, make of the embryonic nesting a very little controlled process. In our approach to the RIF problem, the endometrial biopsy associated with FC and the bacteriology are converted into high value resources in these cases both diagnosis as in the follow-up.

The endometrial biopsy is a minimally invasive and inexpensive method that allows us to diagnose and monitor their response to therapeutic. The association of RIF to endometritis and identification of germs in the cervix and endometrium as Streptococci, Enterococcus faecalis, Escherichia coli, Chlamydia, Mycoplasma Genitalis and N.Gonorrohea has been reported with a frequency of 25 to $50 \%$, adjudging an important role in implantation failure and early abortions where the endotoxin play an important role (Kamiyama et al., 2004; Cicinelli et al., 2008). Johnston-Mac Anany over 30 cases of RIF shows an association with CE of the $30 \%$, with a implantation rate significantly lower in persistent CE (Johnston-MacAnanny et al., 2010). In our study, a high percentage of RIF is associated with CE $14 / 30(46.7 \%)$. On the other hand in the LBR+ we observed a significant endometrial normalization in the posttreatment group; this was absent in LBR-group (Table 3). In terms of results the persistent EC show a significant decrease in implantation rate compared with the groups without endometritis and normalized endometritis posttreatment $(P=0.05)$ and $(P=0.042)$, respectively (Table $5)$. We can say through our observations that a histopathology of CE normalized therapeutically, could be optimize the results although in our study the therapeutic was not able to reverse the $35.7 \%$ of CE. It is opposed to the remissions to near $100 \%$ quoted by other investigation of a RIF series (Johnston-MacAnanny et al., 2010).

RIF in our series is associated with cervical/uterine bacteriology positive in $40 \%$, and $57.1 \%$ associated with CE. In a series of 2190 hysteroscopies made by different indications, 438 corresponded to $\mathrm{CE}$, and of them $88.6 \%$ (388/488) corresponded to CE histology, and where in the $82.4 \%(320 / 388)$ was identified at least an intrauterine microbial agent. The $58 \%$ of the cases were common bacteria, ureaplasma in $10 \%$ and Chlamydia in only $2.7 \%$ (Cicinelli et al., 2008). It has been proposed that the deleterious effect of endotoxin is based on that the trophoblast expresses TLR-4 and TLR-2, both specific for bacterial endotoxins (Abrahams et al., 2004). In our series were identified Mycoplasma and/or Ureaplasma Urealyticum in $41.6 \%$, G- and G+ bacterial germs, predominating entero- bacteria in the $33 \%$ and chlamydias in the $25 \%$. So our data directed to consider endometrial bacterial colonization as an important etiopathogenic factor in CE and RIF, probably associated with other events.

A strong association between endometrial micropolyposis and CE has been previously described. The stromal edema and increased vascularity give the features pictures of 'hillocks' to the hysteroscopy (Cicinelli et al., 2005). In our study was observed a high association of endometrial micropolyposis with $\mathrm{CE}, 42.8 \%(6 / 14)$, and only one case in the absence of CE (6\%) $(1 / 16)$.

In the presence of CE and RIF several authors defend the necessity of using antibiotics and control biopsy with negative bacteriology as normalization criteria. (Mc Queen et al., 2014; Johnston-MacAnanny et al., 2010). In our view the normalization of an affected endometrium requires negative bacteriology, a normal cytometric profile and normal endometrial biopsy; parameters whose regularization occurs in variable periods of time that sometimes exceeding 6 months.

In a systematic review were selected only two works, in which were evaluated the NKu in a population who went to IVF. In neither was able to demonstrate significant differences between patients who achieved pregnancy and those who did not make. Several studies have shown an increase $\mathrm{NKu}$ in patients with recurrent abortion (Lachapelle et al., 1996; Clifford et al., 1999; Tuckerman et al., 2007). It has been suggested that an increased cytotoxic subpopulation CD56-CD16+ in population of recurrent abortion, may be expression of chronic or latent infection (Quenby et al., 2009). In RIF it has been observed an increase of $\mathrm{NKu}$ in relating with implantation failure (Tuckerman et al., 2010). Our findings by endometrial FC show a significant increase in lymphocyte population in RIF pretreatment and posttreatment, compared to the control group. The posttreatment group achieved similar values to the control group (Table 2). When the FC data is analyzed, $\mathrm{LBR}+$ group has a significant decrease of $\mathrm{Li} / \mathrm{PC}$ in the posttreatment, observation also present in LBR-group. But in LBR- group was observed a significant increase in the concentration of $\mathrm{NKu}$, suggesting that the decrease of $\mathrm{NKu}$ in posttreatment is may be predictive in obtaining pregnancy.

In recent years the regulatory $T$ cells have emerged as key players in reproductive immunology. Their diminished with a consequent increase in CD4+ and CD25+ has been linked to the maintenance of self-tolerance (Leber et al., 2010). An increase in CD4+ in the recurrent abortion has been demonstrated, which could be attributed to an increase of macrophages to co-express CD4 and CD14 (Lachapelle et al., 1996). In our study we could demonstrate that when the concentration of CD4 + in post treatment is near to the control values, the reason for chance to live birth increases significantly. Similar behavior was 
observed for histopathological normalization but without being significant (Table 4 ).

It has been pointed out the importance of endometrial thickness thinned, and its pathogenesis has been linked to alterations in the uterine microvasculature. (Miwa et al., 2009; Cohen et al., 2007). A positive relationship between thickness and results in egg donation has been demonstrated, obtaining the best results in live births with endometrium de 9.1 to 10 $\mathrm{mm}$ (Dain et al., 2013). An interesting paper over 1294 transfers with two blastocysts, shows a gradual increase in pregnancy and LBR; but fail to define the cutoff point as to the optimal responsiveness (Richter et al., 2006). In our series, the $20 \%(6 / 30)$ were a thinned endometrium, which in post treatment evaluation show significant thickening, similar to the control group values, although two cases they failed to surpassing the $7 \mathrm{~mm}$ (Table 2).

While it is not the purpose of this study evaluate the impact of endometrial injury in RIF, the fact that our population was subject to multiple biopsies in the previous cycle to the transfer should be discussed. A study of 134 patients with failed IVF and in order to study binding protein was analyzed and surprisingly found a significant increase in the implantation rate and LBR+ (Barash et al., 2003). Subsequently two systematic reviews confirmed the beneficial effect of the endometrial biopsy injury (El-Toukhy et al., 2012; Potdar et al., 2012). Other interventions such as local perfusion of the stimulating factor granulocyte colony in thin endometrium, the routine use of hatching in RIF are part of the arsenal of the combined use of resources that have proven effective (Barad et al., 2014; Hillier et al., 1996).

Is it possible in RIF to define the prognosis of a new transfer? Apparently yes, in presence of CE; as we demonstrated, a normalized endometritis doubles the rate of implantation. We can reverse medically an endometrial factor? Yes, opening the possibility to other therapeutic areas. Facing a patient with RIF is necessary to propose an active behavior both in diagnosis and monitoring as therapeutic.

The merit of this work has been to isolate the endometrial factor in a Recurrence Implantatory Failure population, evaluating time-dependent parameters to the interventions and measuring the results in terms of live birth.

\section{CONCLUSIONS}

a. In the diagnostic stage, a high percentage of RIF it is observed associated with chronic endometritis, thinned out endometrium and endometrial bacterial colonization.

b. We show that a polyvalent therapy is able to normalize histopathology, endometrial ultrasound and concentration of lymphocytes and NK. Chronic persistent endometritis resulted in $5 / 30(16.6 \%)$ after multiple treatments.

c. We show that the treatment established in the group of live birth, significantly decreased the incidence of abnormal histopathology, the concentration of the lymphocytes and NK.

$\mathrm{d}$. The concentration of CD4 + It is highly predictive of live birth.

e. The chronic endometritis normalized by histopathological, bacteriological and cytometric criteria in post treatment, shows a significant increase in implantation rate associated with an increase in the rate of abortion.

f. The persistent chronic endometritis is established as a nosological entity with poor results in terms of rate of implantation and live birth.

Our findings demonstrate the reversibility of endometrial histological changes, both sonographics as immunological in RIF group under a polyvalent therapeutic; which is capable of modifying the immunology and endometrial histopathology and to obtain live birth.

\section{CONFLICT OF INTERESTS}

No conflict of interest have been declared.

\section{Corresponding author:}

Alberto E. Tersoglio

International Center for Assisted Reproduction

Mendoza, Argentina

E-mail: tersoglioa@institutotersoglio.com.ar

\section{REFERENCES}

Abrahams V, Straszewski-Chavez SL, Bole-Aldo P, Romero $\mathrm{R}$, Mor G. Trophoblast apoptosis is induced through toll-like receptor 2, but not toll-like receptor 4: a novel mechanism for first trimester pregnancy failure (abstract). J Soc Gynecol Invest 2004;11:318A.

Alpha Scientists in Reproductive and ESHRE special interest group of Embryology. The Istambul consensus workshop on embryo assessment: proceedings of an expert meeting. Hum Reprod. 2012; 26:1270-83.

Barad DH, Yu Y, KushnirVA, Shohat-Tal A, Lazzaroni E, Lee $\mathrm{H}-\mathrm{J}$, Gleicher N. A randomized clinical trial of endometrial perfusión with granulocyte colony-stimulating factor in in vitro fertilization cycles: impacto on endometrial thickness and clinical pregnancy rates. Ferti Steril 2014; 101:71015 .

Barash A, Deket N, Fieldust S, Segal I, Schechtman E, Granot I. Local injury to the endometrium doubles the incidence of successful pregnancies in patients undergoing in vitro fertilization. Fertil Steril 2003;79:1317-22.

Beer AE, Kwak JY, Ruiz JE. Immunophenotypic profiles of peripheral blood lymphocytes in women with recurrent pregnancy losses and in infertile women with multiple failed in vitro fertilization cycles. Am J Reprod Immunol. 1996; 35: 376-82.

Bryceson YT, March ME, Ljunggren HG, Long EO. Synergy among receptors on resting NK cells for the activation of natural cytotoxicity and cytokine secretion. Blood. 2006; 107:159-66.

Bulmer JN, Lash GE. Human uterine natural killer cells: a reappraisal. Mol Immunol. 2005; 42:511-521.

Cicinelli E, Resta L,Nicoletti R, Zapimbulso V, Tartagani M, Saliani N. Endometrial micropolips at fluid histeroscopy suggest the existence of chronic endometritis. Hum Reprod 2005;20:1386-9.

Cicinelli E, De Ziegler D,Nicoletti R, Colagiglio G, Saliani NResta L, Rizzi D, De Vito D. Chronic endometritis correlation among hysteroscopic, histologic and bacteriologic findings in a prospective trial with 2190 consecutive office hysteroscopies. Fertil Steril 2008;89:677-84.

Clifford K, Flanagan AM, Reagan L. Endometrial CD56+ natural killer cells in women with recurrent miscarriage: a histomorphometric study. Human Reprod 1999;14:2727-30.

Cohen MJ, Rosenzweig TS, Revel A. Uterine abnormalities and embryo implantation: clinical opinion altered by poor debate. Reprod Biomed Online 2007;14:555-8.

Coughlan C, Ledger W, Wang Q, Liu F, Demirol A, Gurgan T, Cutting R, Ong K, Sallam H, Li TC. Recurrent implantation 
failure: definition and management. Reprod Biomed Online. $2014 ; 28: 14-38$.

Coulam CB, Roussev RG. Correlation of NK cell activation and inhibition markers with NK cytotoxicity among women experiencing immunologic implantation failure after in vitro fertilization and embryo transfer. J Assist Reprod Genet. $2003 ; 20$ : 58-62.

Dain L, Bider D, Levron J, Zinchenko V, Westler S, Dirnfeld $M$. Thin endometrium in donor oocyte recipients: enigma or obstacle for implantation? Fertil Steril 2013;100:128995.

El-Toukhy T, Sunkara S, Khalaf Y. Local endometrial injury and IVF outcome: a systematic review and meta-analysis. Reprod Biomed Online. 2012; 25:345-54.

Eschenbach DA. Colonization and infection of the endometrium. In: Aplin JD, Fazleabas AT, Classer SR, Giudice LC, eds. The endometrium, 2nd edn. London: Informa Healthcare Ltd, 2008.

Greenwood SM, Moran JJ. Chronic endometritis: morphologic and clinical observations. Obstet Gynecol. 1981; 58:176-84.

Hillier SL, Kiviat NB, Hawes SE, Hasselquist MB, Hanssen PW, Eschenbach DA, Holmes KK. Role of bacterial vaginosis - associated microorganisms in endometritis. Am J Obstet Gynecol. 1996; 175: 435-41.

Hogan B, Constantini F, Lacy E, eds. Manipulating the Mouse Embryo: a Laboratory Manual. New York: Cold Spring Harbor Laboratory Press, 1986.

Ho HN, Chao KH, Chen CK, Yang YS, Huang SC. Activation status of $\mathrm{T}$ and $\mathrm{NK}$ cells in the endometrium throughout menstrual cycle and normal and anormal early pregnancy. Hum Immunol. 1996; 49:130-6.

Johnston-MacAnanny EB, Harnett J, Engmann LL, Nulsen JC, Sanders MM, Benadiva CA. Chronic endometritis is a frequent finding in women with recurrent implantation failure after in vitro fertilization. Fertil Steril 2010;93: 437-41.

Kamiyama S, Teruya Y, Nohara M, Kanazawa K. Impact of detection of bacterial endotoxin in menstrual effluent on the pregnancy rate in in vitro fertilization and embryo transfer. Fertil Steril 2004; 82:788-92.

Lachapelle MH, Miron P, Hemmings R, Roy DC. Endometrial $T, B$ and NK cells in patients with recurrent spontaneous abortion. Altered profile and pregnancy outcome. J. Immunol. 1996; 156: 4027-34.

Leber A, Teles A, Zenclussen AC. Regulatory T Cells and their role in pregnancy. Am J Reprod Immunol. 2010; 63: 445-59.

Manaster I, Mizrahi S, Goldman-Wohl D, Sela HY, Stern-Ginossar N, Lankry D, Gruda R, Hurwitz A, Bdolah Y, Haimov-Kochman R, Yagel S, Mandelboim O. Endometrial NK cells are special immature cells that await pregnancy. J. Immunol. 2008; 181: 1869-76.

Mc Queen DB, Bernardi LA, Stephenson MD. Chronic endometritis in women with recurrent early pregnancy loss and/ or fetal demise. Fertil Steril 2014; 101:1026-30.
Miwa I, Tamura H, Takasaki A,Yamagata Y, Katsunonosi S, Sugino N. Pathophisiologic features of "thin" endometrium. Fertil Steril 2009;91: 998-1004.

Mjösberg J, Berg G, Ernerudh J, Ekerfelt C. CD4+ CD25+ regulatory $T$ cells in human pregnancy: development of a Treg-MLC-ELISPOT suppression assay and indications of paternal specific Tregs. Immunology. 2007;120: 456-66.

Mjösberg J, Berg G, Jenmalm MC, Ernerudh J. FOXP3+ regulatory $T$ cells and $T$ helper $1, T$ helper 2 , and $T$ helper 17 cells in human early pregnancy decidua. Bio Reprod. 2010; 82: 698-705.

Mor G, Cardenas I. The immune system in pregnancy: a unique complexity. Am J Reprod Immunol. 2010; 63:42533.

Nagamatsu T, Schust DJ. The contribution of macrophages to normal and pathological pregnancies. Am J Reprod Immunol. 2010; 63: 460-71.

Navot D, Scott RT, Droesch K, Veeck LL, Liu HC, Rosenwaks Z.The window of embryo transfer and the efficiency of human conception in vitro. Fertil Steril. 1991; 55: 114-8.

Noyes R, Hertig AT, Rock J. Dating the endometrial biopsy. Fertil Steril 1950; 1: 3-25.

Peirce CS. Selected Philosophical Writings - Volume I (1867 - 1893). In: Houser N, Kloesel C, eds. The Essential Peirce Volume I (1867 - 1893). Indiana University Press, 1992.

Polanski LT, Baumgarten MN, Quenby S, Brosens J, Campbell BK, Raine-Fenning NJ What exactly do we mean by recurrent implantation failure? A systematic review and opinion. Reprod Biomed Online. 2014;28:409-23.

Potdar N, Gelbaya T, Nardo LG. Endometrial injury to overcome recurrent embryo implantation failure: a systematic review and meta-analysis. Reprod Biomed Online. 2012; 25:565-71.

Quenby S, Nik H, Innes B, Lash G, Turner M, Drury J, Bulmer J. Uterine natural killer cells and angiogenesis in recurrent reproductive failure. Hum Reprod. 2009; 24: 45-54.

Richter KS, Bugge KR, Bromer JG, Levy MJ. Relationship between endometrial thickness and embryo implantation, based on 1,294 cycles of in vitro fertilization with transfer of two blastocyst-stage embryos. Fertil Steril 2006;87: 53-9.

Samaja J. ed Epistemología y Metodología - Elementos para una teoría de la investigación científica. Buenos Aires, Eudeba, 1999.

Salatino DR. Semiótica de los sistemas reales [thesis]. Doctoral Thesis in Literature, Psycholinguistics specialty by the Faculty of Philosophy and Letters. National University of Cuyo, Mendoza, Argentina, 2009.

Strowitzki T, Germeyer A, Popovici R, von Wolff M. The human endometrium as a fertility-determinig factor. Hum Reprod Update. 2006;12:617-30.

Tuckerman E, Laird SM, Prakash A, Li TC. Prognostic value 
of the measurement of uterine natural killer cells in the endometrium of women with recurrent miscarriage. Hum Reprod. 2007; 22:2208-13.

Tuckerman E, Mariee N, Prakash A, Laird SM, Li TC. Uterine natural killer cells in peri-implantation endometrium from women with repeated implantation failure after IVF. J Reprod Immunol 2010;87:60-6.

Zenke U, Chetkowski RJ. Transfer and uterine factors are the major recipient-related determinants of success with donor eggs. Fertil Steril. 2004; 82:850-6. 